\title{
Low Level of 25(OH)D Aggravates Target Organ Damage of Elderly Type 2 Diabetes
}

\author{
Hongfeng Jiang ${ }^{1}$, Shaorong Peng ${ }^{1}$, Zhangqiang Guo ${ }^{2}$, Caihua Huang ${ }^{1} \&$ Jie Zhang $^{1}$ \\ ${ }^{1}$ Geriatrics Department, Wuhan Fourth Hospital; Puai hospital, Tongji Medical College, Huazhong University of \\ Science and Technology, Wuhan, China \\ ${ }^{2}$ Department of Emergency, Wuhan Fourth Hospital; Puai hospital, Tongji Medical College, Huazhong University \\ of Science and Technology, Wuhan, China \\ Correspondence: Hongfeng Jiang, Geriatrics Department, Puai hospital, Tongji Medical College, Huazhong \\ University of Science and Technology, Wuhan 430033, China. Tel: 86-136-5989-9725. Fax: 86-027-6883-1400. \\ E-mail: jhf2@sina.com
}

Received: November 19, 2019 Accepted: April 17, 2020 Online Published: May 8, 2020

doi:10.5539/gjhs.v12n7p1 URL: https://doi.org/10.5539/gjhs.v12n7p1

Abbreviations: $25(\mathrm{OH}) \mathrm{D}=25$-hydroxyvitamin $\mathrm{D}, \mathrm{BMI}=$ body mass index, HDL-C=high-density lipoprotein cholesterol, LDL-C $=$ low-density lipoprotein cholesterol, hsCRP=high-sensitivity C-reactive protein, $\mathrm{PTH}=$ parathyroid hormone, $\mathrm{LVMI}=$ left ventricular absolute mass index, $\mathrm{CcR}=$ creatinine clearance rate, $\mathrm{ACR}=$ urine albumin/uric creatinine ratio, cIMT $=$ carotid intimal media thickness, HbAlc $=$ hemoglobin A1c, MMP $=$ matrix metalloproteinases.

\begin{abstract}
Background: It is unclear about the association between vitamin D level and target organ damage in elderly patients with type 2 diabetes in China. Aim of this study was to investigate the relationship between vitamin D level and target organ damage in elderly patients with type 2 diabetes of Chinese population.
\end{abstract}

Methods: A retrospective study was performed on 254 elderly patients with type 2 diabetes (148 males and 106 females). According to assay of 25-hydroxy vitamin $\mathrm{D}[25(\mathrm{OH}) \mathrm{D}]$, the participants were divided into a deficiency group $(n=129)$, an insufficiency group $(n=77)$ and a sufficiency group $(n=48)$. The clinical indicators of target organ damages among these groups were analyzed, and multivariate logistic regression analysis was performed to predict the target organ damage.

Results: Approximately $81.1 \%$ of patients were the low level of $25(\mathrm{OH}) \mathrm{D}$ with mean $25(\mathrm{OH}) \mathrm{D}$ below $30 \mathrm{ng} / \mathrm{ml}$. When compared with those in the sufficiency group, the level of left ventricular absolute mass index (LVMI), the morning urine albumin/uric creatinine ratio (ACR) and carotid intimal medial thickness (cIMT) increased significantly and creatinine clearance rate $(\mathrm{CcR})$ decreased significantly in the deficiency group $(\mathrm{P}<0.05)$. The level of ACR and cIMT in the insufficiency group also increased significantly $(\mathrm{P}<0.05)$. There was a higher proportion in kidney, brain, artery and total target organ damage in the deficiency group or insufficiency group than those in the sufficiency group $(\mathrm{P}<0.05)$. Logistic regression analysis showed that low-level $25(\mathrm{OH}) \mathrm{D}(<$ $30 \mathrm{ng} / \mathrm{ml}$ ) was independently associated with total target organ damage in patients with elderly type 2 diabetes (OR $=3.58 ; 95 \%$ CI: $1.60-8.02, P=0.002$ )

Conclusions: A condition of hypovitaminosis D is commonly present in Chinese patients with elderly type 2 diabetes. The low level of 25(OH)D may contribute to aggravate target organ damage of elderly type 2 diabetes.

Keywords: 25 -hydroxy vitamin D [25(OH)D], type 2 diabetes, proteinuria, left ventricular hypertrophy, target organ damage

\section{Introduction}

Type 2 diabetes can shorten a patient's life expectancy by 10 years (Shlomo et al., 2005). As of 2015 it was assessed that there were approximately 435 million cases with diabetes within the globe (Vos et al., 2016). The overall prevalence of diabetes was estimated to be $11.6 \%$ in the Chinese adult population by the 2010 China noncommunicable disease surveillance group (Xu et al., 2013). The leading causes of death and disability of type 2 diabetes are chronic target organ damage, including heart, brain and kidney damage. Among them, 75-80\% patients with diabetes died from macroangiopathy, especially from cardiovascular disease. The prevalence of 
coronary artery disease in diabetic patients increased by 2 to 4 times compared to that in patients without diabetes. Patients with diabetes have 2 times higher incidence to have cerebrovascular disease than non-diabetic patients. Furthermore, cerebrovascular disease associated with diabetes had a poor prognosis and high mortality. So diabetes was regarded to have the same risk as cardiovascular adisease or coronary heart disease.

Individuals absorb vitamin D from synthesis in vivo, dietary intake, or supplements. Vitamin D is metabolized to 25-hydroxy vitamin $\mathrm{D}[25(\mathrm{OH}) \mathrm{D}]$ in the liver, which is then metabolized to 1,25-dihydroxyvitamin D $\left[1,25(\mathrm{OH})_{2} \mathrm{D}\right]$ in the kidneys. $1,25(\mathrm{OH})_{2} \mathrm{D}$ is the biologically active form. The synthesis of $1,25(\mathrm{OH})_{2} \mathrm{D}$ in renal is regulated by parathyroid hormone (PTH), serum calcium and phosphorus. Except affecting the skeleton, 25(OH)D was highly associated with various chronic diseases such as type 2 diabetes, cardiovascular disease, metabolism syndrome, cancer and so on. In our past study we found that elderly Chinese people were widespread with 25(OH)D deficiency and insufficiency (Jiang \& Peng, 2014). It has been reported that the serum level of 25(OH)D was very low in patients with coronary heart disease, chronic cardiac failure, chronic renal insufficiency, and type 2 diabetes combined with cardiovascular disease has a lower level of 25(OH)D than cardiovascular disease alone (Cigolini et al., 2006).We speculate that low 25(OH)D level is in association with target organ damage in patient with type 2 diabetes. This study is designed to evaluate the relationship between $25(\mathrm{OH}) \mathrm{D}$ (a marker to evaluate vitamin $\mathrm{D}$ status) and target organ damage in Chinese elderly type 2 diabetes.

\section{Methods}

We retrospectively enrolled 294 elderly patients with type 2 diabetes who were hospitalized in the geriatrics department of Puai hospital (Puai hospital, Tongji Medical College, Huazhong University of Science and Technology) between the period from Jun 2014 to Mar 2017. We also included 254 patients with non-new-onset diabetics in the study, who have undergone systematic diabetes treatment for at least six months prior to admission and vitamin testing. 40 patients were excluded. Exclusion criteria were the patients with acute disease, chronic active liver disease, severe kidney disease (CKD4-5), patients who took taking drugs influencing vitamin D metabolism within three months or any incomplete information (Figure 1). Those participants had 148 males and 106 females, aginge from 60-94 years old and with the average age of $74.5 \pm 8.0$ years. All the patients from urban areas in China met the diagnosis standards of type 2 diabetes enacted by WHO in 1999. All patients had clinical demographics, duration of diabetes, and risk factors (including hypertension, dyslipidemia, current smoking and other life style, and family history). Serum lipid, serum glucose and other biochemical indicators were detected in venous blood which drawled next morning after hospitalization.

\subsection{Serum Level Measurement of 25(OH)D, PTH and Osteocalcin}

Venous blood samples for the detection of $25(\mathrm{OH}) \mathrm{D}$, PTH, osteocalcin and HBA1C were drawn after a 12-hour fast and an empty stomach decubitus for $30 \mathrm{~min}$ in the next morning. Blood samples were then collected for routine analysis and examination of liver and kidney function, blood lipids and other tests were conducted. Levels of serum 25(OH)D and serum PTH were measured by Wuhan center for Clinical laboratory (Wuhan, China) using electrochemiluminescent immunoassay (ECLIA) kit from Roche Diagnostics (Shanghai) Ltd. The intra-assay coefficient of variation for $25(\mathrm{OH}) \mathrm{D}$ and $\mathrm{PTH}$ were $5.2 \%$ and $6.7 \%$ respectively.

The vitamin D deficiency was defined as serum 25(OH)D below 20ng $/ \mathrm{ml}$, vitamin D insufficiency was between 20 $\mathrm{ng} / \mathrm{ml}$ and $30 \mathrm{ng} / \mathrm{ml}$, and vitamin D sufficiency was more than $30 \mathrm{ng} / \mathrm{ml}$ (Holick et al.,2012). According to this classification, 129 patients were divided into deficiency group, 77 patients in the insufficiency group and 48 patients in the sufficiency group. In this study, 25(OH)D deficiency and insufficiency were collectively named as low level of 25(OH)D.

\subsection{Criteria of Target Organ Damage}

Target organ damage in diabetes mainly includes vascular damage and microvascular damage, while in this study we focus on the damage of the heart, brain and kidney. These damage are evaluated by ventricular hypertrophy, ventricular systolic dysfunction, brain damage, impaired renal function, carotid plaque and so on. The detailed evaluation methods are as follows:

1) Left ventricular hypertrophy (LVH): Color Doppler echocardiography diagnosis instrument was used to measure the left ventricular end diastolic diameter, and the left ventricular posterior wall thickness. The left ventricular absolute mass index (LVMI) was calculated by the Devereux formula. When the LVMI was more than $125 \mathrm{~g} / \mathrm{m}^{2}$ in male and $120 \mathrm{~g} / \mathrm{m}^{2}$ in female, this was considered to be left ventricular hypertrophy.

2) Left ventricular systolic dysfunction (LVSDF): LVEF is less than $50 \%$.

3) Cerebral target organ damage: obvious cerebral arterial thrombosis, cerebral hemorrhage, history of transient 
ischemic attack, radiographic evidence of brain damage by CT or MRI.

4) Renal target organ damage: creatinine clearance rate (Ccr) is less than $50 \mathrm{ml} / \mathrm{min}$ and the morning urine albumin/uric creatinine ratio (ACR) is more than $30 \mathrm{mg} / \mathrm{g}$.

5) Arterial target organ damage: there are atheromatous plaques in carotid artery. GE LOGIQ 9 color flow Doppler zoography is used to measure intimal medial thickness (IMT) and the transducer frequency is 10-12 MHZ.The left and right common carotid art eries below carotid sinus $1 \mathrm{~cm}$ (no patch site) were measured 5 times IMT respectively and the mean level of 10 values was the carotid IMT (cIMT). When cIMT is more than $1.0 \mathrm{~mm}$ or there are atheromatous plaques (local eminence, incrassation, protruding into the lumen, and the cIMTis more than $1.2 \mathrm{~mm}$ ), this is considered a standard for large artery damage. In this study, when any indicator mentioned above was positive, it was the target organ damage.

294 elderly patients with type 2 diabetes who were hospitalized in geriatrics department of Puai hospital in the period from Jun 2014 to Mar 2017.

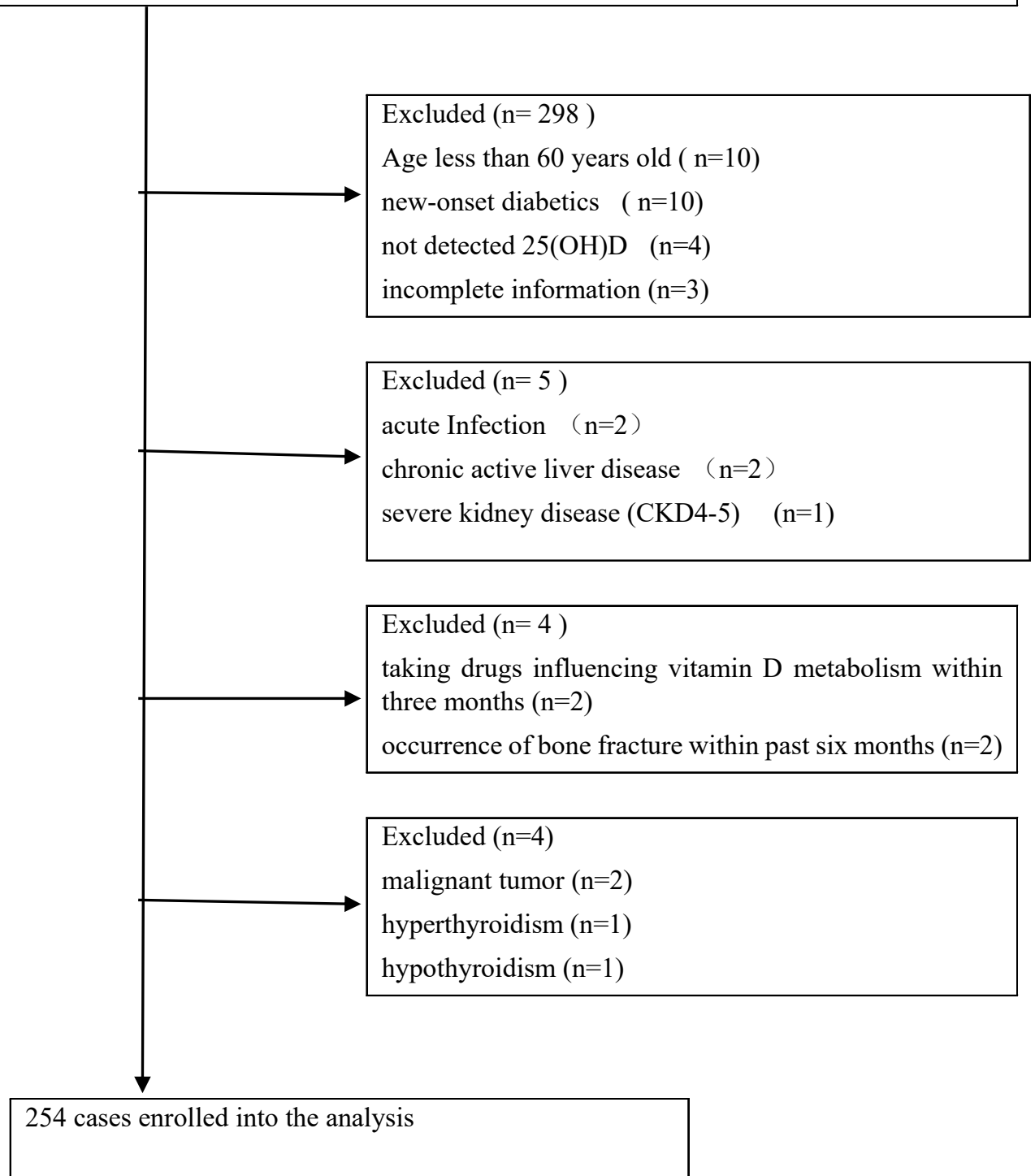

Figure 1. Flow chart for the selection of the study subject 


\subsection{Statistical Analysis}

Data was analyzed by SPSS 16.0 software [SPSS Inc, Chicago, IL]. Continuous variables were presented as mean \pm standard deviation (SD). For multiple comparison (three groups), analysis of variance (ANOVA) was used to assess the differences among the three groups. LSD-t-test was performed to compare the differences between low level of 25(OH)D group and sufficiency group. Categorical variables were presented as frequencies (percentage), and the chi-square test of proportion was performed. Multiple logistic regression analysis was used to determine the factor associated with target organ damage, covariates age, gender, blood pressure, BMI, LDL-C, 25(OH)D, HBA1C, drinking, smoking, hypertension duration were taken as parameters, which were entered into the model based on their potential roles. The level of significance was set as $\mathrm{p}<0.05$.

\section{Results}

\subsection{Comparison of Clinical Characteristics of Elderly Type 2 Diabetes With Different Level of 25(OH)D}

Characteristics of participants in the study were summarized in Table 1. Sufficiency ( $>30 \mathrm{ng} / \mathrm{mL})$, insufficient $(20$ $30 \mathrm{ng} / \mathrm{mL}$ ), and deficient $(<20 \mathrm{ng} / \mathrm{mL})$ levels of $25(\mathrm{OH}) \mathrm{D}$ were present in $18.9 \%, 30.3 \%$, and $50.8 \%$, respectively. Approximately $81.1 \%$ of patients were the low level of $25(\mathrm{OH}) \mathrm{D}$ with mean $25(\mathrm{OH}) \mathrm{D}$ below $30 \mathrm{ng} / \mathrm{ml}$. According to assay of $25(\mathrm{OH}) \mathrm{D}$, the participants were divided into a deficiency group $(\mathrm{n}=129)$, an insufficiency group $(\mathrm{n}=77)$ and sufficiency group $(\mathrm{n}=48)$. The levels of $25(\mathrm{OH}) \mathrm{D}$ were $12.17 \pm 4.24 \mathrm{ng} / \mathrm{mL}, 23.58 \pm 2.74 \mathrm{ng} / \mathrm{mL}, 35.10 \pm 3.70$ $\mathrm{ng} / \mathrm{mL}$, respectively. Age-and sex-adjusted mean 25[OH]D levels for elderly type 2 diabetes subjects were $23.64 \pm$ $0.26 \mathrm{ng} / \mathrm{mL}$.

There were significant differences among three groups on proportions of hypertension, coronary heart disease, smoking history case, and the levels of total cholesterol, low-density lipoprotein cholesterol (LDL-C) and hemoglobin Alc $(\mathrm{HbA1c})(\mathrm{P}<0.05)$; while there was no significant difference on sex, alcoholic, BMI, diabetes, and the levels of high-density lipoprotein cholesterol (HDL-C), serum calcium, triglyceride, high-sensitivity C-reactive protein (hsCRP), parathyroid hormone $(\mathrm{PTH})$, osteocalcin $(\mathrm{P}>0.05)$. Further analysis found that the differences of coronary heart disease, smokers and the level of total cholesterol, LDL-C among three groups mainly came from between deficiency group and sufficiency group $(\mathrm{P}<0.05)$; while the differences between insufficiency group and sufficiency group only existed in the number of hypertensive patients and the level of HBA1C $(\mathrm{P}<0.05)$ (Table 1).

Table 1. Characteristics of participants included in the study

\begin{tabular}{|c|c|c|c|c|}
\hline Items & $\begin{array}{l}\text { Deficiency group (129 } \\
\text { cases) }\end{array}$ & $\begin{array}{l}\text { Insufficiency group (77 } \\
\text { cases) }\end{array}$ & $\begin{array}{l}\text { Sufficiency group } \\
\text { ( } 48 \text { cases) }\end{array}$ & $\begin{array}{l}P \\
\text { value }\end{array}$ \\
\hline Age (year) & $74.7 \pm 8.3$ & $75.3 \pm 8.1$ & $72.5 \pm 6.7$ & 0.142 \\
\hline Sex (male/female) & $81 / 48$ & $40 / 37$ & $27 / 21$ & 0.297 \\
\hline BMI $\left(\mathrm{kg} / \mathrm{m}^{2}\right)$ & $25.2 \pm 2.5$ & $24.8 \pm 2.4$ & $24.3 \pm 3.8$ & 0.082 \\
\hline Diabetes duration (year) & $8.7 \pm 3.3$ & $8.3 \pm 3.5$ & $7.9 \pm 3.4$ & 0.354 \\
\hline Hypertension [cases (\%)] & $88(68.2)^{\mathrm{a}}$ & $46(59.7)^{\mathrm{a}}$ & $20(41.7)$ & 0.006 \\
\hline Coronary heart disease [cases (\%)] & $79(61.2)^{\mathrm{a}}$ & $40(51.9)$ & $18(37.5)$ & 0.017 \\
\hline Triglyceride (mmol/L) & $1.46 \pm 0.76$ & $1.45 \pm 0.76$ & $1.44 \pm 0.67$ & 0.974 \\
\hline total cholesterol $(\mathrm{mmol} / \mathrm{L})$ & $4.75 \pm 0.98^{\mathrm{a}}$ & $4.48 \pm 0.73$ & $4.40 \pm 0.83$ & 0.025 \\
\hline LDL-C (mmol/L) & $3.43 \pm 1.07^{\mathrm{a}}$ & $3.06 \pm 0.83$ & $3.11 \pm 0.77$ & 0.015 \\
\hline HDL-C (mmol/L) & $1.11 \pm 0.13$ & $1.08 \pm 0.13$ & $1.08 \pm 0.11$ & 0.209 \\
\hline Serum calcium $(\mathrm{mmol} / \mathrm{L})$ & $2.05 \pm 0.20$ & $2.06 \pm 0.21$ & $2.04 \pm 0.22$ & 0.868 \\
\hline $\mathrm{HsCRP}(\mathrm{mg} / \mathrm{L})$ & $4.6 \pm 2.3$ & $5.1 \pm 2.5$ & $4.3 \pm 2.3$ & 0.151 \\
\hline HBA1C (\%) & $6.8 \pm 1.0^{\mathrm{a}}$ & $6.8 \pm 1.0^{\mathrm{a}}$ & $6.3 \pm 0.8$ & 0.010 \\
\hline PTH (pg/ml) & $52.1 \pm 22.7$ & $48.8 \pm 20.8$ & $45.8 \pm 16.8$ & 0.184 \\
\hline Osteocalcin (ng/ml) & $22.36 \pm 14.18$ & $21.46 \pm 13.23$ & $20.09 \pm 12.11$ & 0.604 \\
\hline Smoking history [cases (\%)] & $62(48.1)^{\mathrm{a}}$ & $25(32.5)$ & $16(33.3)$ & 0.046 \\
\hline Drinking history [cases (\%)] & $3(27.1)$ & $18(23.4)$ & $12(25.0)$ & 0.832 \\
\hline
\end{tabular}


Data is presented as mean \pm SD for continuous variables and numbers (percentages) for dichotomous variables. Differences were assessed by the LSD-t-test (for continuous variables) and by the chi-square test (for categorical variables). BMI indicates body mass index; DBP, diastolic blood pressure; HDL-C, high-density lipoprotein cholesterol; LDL-C, low-density lipoprotein cholesterol; SBP, systolic blood pressure; HsCRP, high-sensitivity C-reactive protein; PTH, parathyroid hormone; HbAlc,hemoglobin A1c; ${ }^{\text {a }}$ analysis of variance with LSD-t-test or chi-square test: $P<005$ versus Sufficiency group.

\subsection{Comparison of Target Organ Damage Indicators Among Three Groups}

There were significant differences on Ccr, LVMI, ACR and cIMT $(\mathrm{P}<0.05)$. When compared with those in the sufficiency group, the level of LVMI, ACR and cIMT increased significantly and CcR decreased significantly in deficiency group $(\mathrm{P}<0.05)$. Furthermore, ACR and cIMT in the insufficiency group also increased significantly $(\mathrm{P}<0.05)$, but the decrease of $\mathrm{Ccr}$ was not obvious in insufficiency group $(\mathrm{P}>0.05)$. see Table 2 .

Table 2. Comparison of target organ damage indicators between three groups

\begin{tabular}{|c|c|c|c|c|}
\hline Items & $\begin{array}{l}\text { Deficiency group } \\
\text { (129 cases) }\end{array}$ & $\begin{array}{l}\text { Insufficiency group (77 } \\
\text { cases) }\end{array}$ & $\begin{array}{l}\text { Sufficiency group (48 } \\
\text { cases) }\end{array}$ & $P$ value \\
\hline $\operatorname{Ccr}(\mathrm{ml} / \mathrm{min})$ & $60.3 \pm 11.4^{\mathrm{a}}$ & $63.8 \pm 12.0$ & $65.3 \pm 12.3$ & 0.0185 \\
\hline $\mathrm{ACR}(\mathrm{mg} / \mathrm{g})$ & $32.2 \pm 11.7^{\mathrm{a}}$ & $30.8 \pm 15.3^{\mathrm{a}}$ & $26.4 \pm 13.2$ & 0.0349 \\
\hline $\operatorname{LVMI}\left(\mathrm{g} / \mathrm{m}^{2}\right)$ & $116.5 \pm 13.8^{\mathrm{a}}$ & $114.8 \pm 13.3^{\mathrm{a}}$ & $110.7 \pm 12.7$ & 0.0022 \\
\hline cIMT (mm) & $1.08 \pm 0.20^{\mathrm{a}}$ & $1.01 \pm 0.24^{\mathrm{a}}$ & $0.90 \pm 0.18$ & 0.0000 \\
\hline
\end{tabular}

Ccr indicates creatinine clearance rate; LVMI, left ventricular absolute mass; ACR, urine albumin/uric creatinine ratio; cIMT, carotid intimal-media thickness; ${ }^{a}$ analysis of variance with LSD-t-test or chi-square test: $P<005$ versus Sufficiency group.

\subsection{Comparison of Different Target Organ Damage Among Three Groups}

Total target organ damage cases were the cases of any target organ damage. There were significant differences among the three groups on renal, cerebral, arterial and total target organ damage and $\mathrm{LVH}(\mathrm{P}<0.05)$, while there was no difference among the three groups on LVSDF $(\mathrm{P}>0.05)$. There was a higher proportion in renal, cerebral, arterial and total target organ damage in deficiency group or insufficiency group than those in the sufficiency group $(\mathrm{P}<0.05)$. (Table 3).

Table 3. Comparison of the target organ damage among three groups

\begin{tabular}{|c|c|c|c|c|}
\hline Items & $\begin{array}{l}\text { Deficiency group } \\
\text { (129 cases) }\end{array}$ & $\begin{array}{l}\text { Insufficiency group } \\
\text { ( } 77 \text { cases) }\end{array}$ & $\begin{array}{l}\text { Sufficiency group } \\
\text { ( } 48 \text { cases) }\end{array}$ & $P$ value \\
\hline LVSDF [cases (\%)] & $45(34.9)$ & $21(27.3)$ & $12(25.0)$ & 0.3299 \\
\hline LVH $[\operatorname{cases}(\%)]$ & $72(55.8)^{\mathrm{a}}$ & $36(46.8)$ & $16(33.3)$ & 0.0265 \\
\hline Renal TOD [cases (\%)] & $78(60.5)^{\mathrm{a}}$ & $37(48.1)^{\mathrm{a}}$ & $20(41.7)$ & 0.0469 \\
\hline Cerebral TOD [cases (\%)] & $52(40.3)^{\mathrm{a}}$ & $30(39.0)^{\mathrm{a}}$ & $10(20.8)$ & 0.0473 \\
\hline Arterial TOD [cases (\%)] & $65(50.4)^{\mathrm{a}}$ & $36(48.1)^{\mathrm{a}}$ & $14(29.2)$ & 0.0368 \\
\hline Total TOD [cases (\%)] & $108(83.7)^{\mathrm{a}}$ & $56(72.7)^{\mathrm{a}}$ & $23(47.9)$ & 0.0000 \\
\hline
\end{tabular}

LVSDF: left ventricular systolic dysfunction; LVH: left ventricular hypertrophy; TOD: target organ damage. ${ }^{\text {a }}$ analysis of variance with LSD-t-test: $P<005$ versus Sufficiency group.

\subsection{Comparison of Related Indicators Between Target Organ Damage Group and No Target Organ Damage Group}

The group with target organ damage had lower levels of 25(OH)D than the group without target organ damage $(\mathrm{p}<0.01)$ in Table 4. This difference persisted even after adjustment for risk factors such as age, gender, smoking, hypertension and coronary heart disease, diabetes mellitus, and HBA1C.The adjusted levels of 25(OH)D in the group with and without target organ damage were $18.72 \pm 1.20 \mathrm{ng} / \mathrm{mL}$ and $27.04 \pm 1.93 \mathrm{ng} / \mathrm{mL}$, respectively 
$(\mathrm{p}<0.01)$.

Table 4. Comparison of related indicators between target organ damage group and no target organ damage group

\begin{tabular}{lllc}
\hline Items & $\begin{array}{l}\text { The group with target organ } \\
\text { damage }(\mathrm{n}=187)\end{array}$ & $\begin{array}{l}\text { The group without target } \\
\text { damage }(\mathrm{n}=67)\end{array}$ & $\begin{array}{l}\text { organ } \\
\text { value }\end{array}$ \\
\hline Age (years) & $74.8 \pm 8.1$ & $73.7 \pm 7.5$ & 0.352 \\
BMI $\left(\mathrm{kg} / \mathrm{m}^{2}\right)$ & $25.2 \pm 2.5$ & $24.3 \pm 2.4$ & 0.013 \\
TG $(\mathrm{mmol} / \mathrm{L})$ & $1.43 \pm 0.71$ & $1.51 \pm 0.84$ & 0.457 \\
HDL-C (mmol/L) & $0.82 \pm 0.31$ & $0.86 \pm 0.29$ & 0.233 \\
LDL-C (mmol/L) & $3.36 \pm 1.00$ & $2.95 \pm 0.78$ & 0.003 \\
HBA1C (\%) & $6.82 \pm 0.97$ & $6.38 \pm 0.93$ & 0.001 \\
25(OH)D (ng/mL) & $18.3 \pm 8.8$ & $24.6 \pm 10.2$ & 0.000 \\
Sex (male/female) & $113 / 74$ & $35 / 32$ & 0.243 \\
Hypertension [cases (\%)] & $140(74.8)$ & $14(20.9)$ & 0.000 \\
Coronary heart disease [cases (\%)] & $108(57.8)$ & $29(43.3)$ & 0.041 \\
Smoking history [cases (\%)] & $92(49.2)$ & $11(16.4)$ & 0.000 \\
High LDL-C [cases (\%)] & $142(75.9)$ & $34(50.7)$ & 0.000 \\
High HBA1C [cases (\%)] & $75(40.1)$ & $10(14.9)$ & 0.000 \\
Low 25(OH)D [cases (\%)] & $164(87.7)$ & $42(62.7)$ & 0.000 \\
\hline
\end{tabular}

Data was presented as mean \pm SD for continuous variables and number (percentages) for dichotomous variables. Differences were assessed by the LSD-t-test (for continuous variables) and by the chi-square test (for categorical variables). BMI indicates body mass index; DBP, diastolic blood pressure; HDL-C, high-density lipoprotein cholesterol; LDL-C, low-density lipoprotein cholesterol; SBP, systolic blood pressure; HnCRP, high-sensitivity C-reactive protein; PTH, parathyroid hormone; HbA1c,hemoglobin A1c; High LDL-C :LDL-C $\geq 2.6 \mathrm{mmol} / \mathrm{L}$; High HBA1C: High HBA1C $\geq 7.0 \%$; Low 25(OH)D $\leq 30 \mathrm{ng} / \mathrm{ml}$.

a analysis of variance with LSD-t-test or chi-square test: $P<005$ versus Sufficiency group.

3.5 Multiple Logistic Regression Analysis of Factors That Caused Target Organ Damage of Elderly Type 2 Diabetes

We set $\mathrm{HbA} 1 \mathrm{C} \geq 7.0 \%$ after treatment for high $\mathrm{HbA} 1 \mathrm{C}, \mathrm{LDL}-\mathrm{C}>2.5 \mathrm{mmol} / \mathrm{L}$ for high LDL-C (Herma, Peterse, \& Kalyan, 2017).We took the total target organ damage as a dependent variable. Age, sex, blood pressure, BMI, LDL-C, 25(OH)D, HBA1C, drinking, smoking, hypertension and diabetes duration were factors, which were independent variables and incorporated into the multivariable logistic regression model.Backward elimination was used to perform logistic regression analysis. Multiple logistic regression analysis showed that low-level 25(OH)D $(<30 \mathrm{ng} / \mathrm{ml})$, high-level LDL-C ( $>2.5 \mathrm{mmol} / \mathrm{L})$, high-level HBA1C $(\geq 7.0 \%)$, hypertension and smoking were risk factors of total target organ damage in Table 5. Meanwhile, serum low-level 25(OH)D was independently associated with the incidence of total target organ damage in patients with elderly type 2 diabetes $(\mathrm{OR}=3.58$; $95 \%$ CI: $1.60-8.02, \mathrm{P}=0.002$ ). 
Table 5. Multivariable logistic regression analysis in target organ damage of elderly diabetes

\begin{tabular}{llllll}
\hline Independent variable & Coefficient $\beta$ & standard errors $_{\mathrm{x}}$ & Wald $\chi^{2}$ test & $P$ value & OR $(95 \%$ confidence interval $)$ \\
\hline Constants & -4.818 & 0.665 & 52.526 & 0.001 & \\
Low 25(OH)D $(<30 \mathrm{ng} / \mathrm{ml})$ & 1.276 & 0.411 & 9.633 & 0.002 & $3.58(1.60-8.02)$ \\
High LDL-C $(\geq 2.6 \mathrm{mmol} / \mathrm{L})$ & 0.903 & 0.398 & 5.158 & 0.023 & $2.47(1.13-5.38)$ \\
High HBA1C $(\geq 7.0 \%)$ & 1.144 & 0.443 & 6.671 & 0.010 & $3.14(1.32-7.47)$ \\
Smoking & 1.777 & 0.451 & 15.536 & 0.001 & $5.92(2.44-14.31)$ \\
Hypertension & 1.963 & 0.390 & 25.365 & 0.001 & $7.12(3.32-15.28)$
\end{tabular}

LDL-C indicates low-density lipoprotein cholesterol; 25(OH)D, 25-hydroxyvitamin D. High LDL-C :LDL-C $\geq 2.6 \mathrm{mmol} / \mathrm{L}$ ); High HBA1C: High HBA1C $\geq 7.0 \%$; Low $25(\mathrm{OH}) \mathrm{D} \leq 30 \mathrm{ng} / \mathrm{ml}$.

\section{Discussion}

In serum, the level of $25(\mathrm{OH}) \mathrm{D}$ is 1000 times higher than that of $1,25(\mathrm{OH})_{2} \mathrm{D}$, which also shows a rather close linear correlation between $25(\mathrm{OH}) \mathrm{D}$ and $1,25(\mathrm{OH})_{2} \mathrm{D} .1,25(\mathrm{OH}) 2 \mathrm{D}$ has a short half-life period and instability in vitro, so serum $1,25(\mathrm{OH})_{2} \mathrm{D}$ is not suitable as a clinical biomarker assess vitamin $\mathrm{D}$ status. $25(\mathrm{OH}) \mathrm{D}$ is easy to be detected and has a relatively long half-life, therefore the level of serum $25(\mathrm{OH}) \mathrm{D}$ provides a clinically useful assessment of an individual's vitamin D status. Some studies have confirmed that vitamin D has an important impact on other system related diseases, in addition to in calcium and bone metabolism. Some studies have shown that vitamin D plays an important role in other system related diseases, in addition to the regulation of calcium homeostasis and bone metabolism.

In our study, the proportion of deficient patients and insufficient patients was $81.8 \%$ in all type 2 diabetes. Those demonstrated that vitamin D deficiency and insufficiency were very common in elderly type 2 diabetes in China. The $25(\mathrm{OH}) \mathrm{D}$ deficiency group and insufficiency groups had more frequent target organ damage than the sufficiency group in this study, Furthermore, there was also more target organ damage in deficient than insufficiency groups. This supports that lower $25(\mathrm{OH}) \mathrm{D}$ levels have the more severe target organ damage. The reason might be that low levels of $25(\mathrm{OH}) \mathrm{D}$ increased the prevalence of diabetes, hypertension and metabolic syndrome. It also increased the degree of atherosclerosis, increased the incidence and severity of coronary heart disease, and cerebral infarction and aortic disease.

It has been reported that 25(OH)D synthesis maybe decreasing in diabetes mainly because of the energy metabolism abnormalities or because of the reduction of outdoor activities leading to the decrease of vitamin D synthesis induced by ultraviolet ray radiation. What's more, low-level 25(OH)D is ubiquitous worldwide and $25(\mathrm{OH}) \mathrm{D}$ deficiency and insufficiency is especially obvious in elderly. One meta-analysis demonstrated that the level of $25(\mathrm{OH}) \mathrm{D}$ was negatively associated with the risk of type 2 diabetes, and this negative association still existed after adjusting sex, age, BMI and other factors (Song et al., 2013).

Our study found that there were significant differences in the level of TC, LDL-C and HBA1C between 25(OH)D the deficiency group, 25(OH)D sufficiency group and 25(OH)D insufficiency group. These differences mainly came from the deficiency group and insufficiency group after analysis between two groups. Vitamin D receptor is ubiquitous in various tissues, and it is demonstrated that vitamin D could participate in energy, glucose and lipid metabolism (Fraser, 2015). One cross-sectional study (Martin, 2007) including 15088 participants also got the similar conclusion. This study indicated that when compared with the sufficiency group, the deficiency group had a higher morbidity in hypertension, diabetes and hyperlipemia. Our study also demonstrated that a low-level of 25(OH)D elderly diabetes had a higher morbidity of hypertension. Due to advance diagnosis and treatment, there were no differences in systolic pressure, diastolic pressure, fasting plasma glucose and postprandial plasma glucose between three groups.

This study found that the $25(\mathrm{OH}) \mathrm{D}$ deficiency group and insufficiency group had a higher proportion in coronary heart disease, brain and artery damage when compared with the sufficiency group and the differences were significant. The main pathological basis of coronary heart disease, brain and artery damage is atherosclerosis. The expression of vitamin D receptor is ubiquitous in the regulation of multiple cytokines and gene transcription in immune cells in human tissues. This phenomenon demonstrated that $1,25(\mathrm{OH})_{2} \mathrm{D}$ not only acts as a calcium regulator, but also participates in inflammatory responses, immunity and other pathological and physiological processes influencing the prognosis of chronic diseases (Papandreou \& Hamid, 2015). Oh showed that 1, 
$25(\mathrm{OH})_{2} \mathrm{D}$ could inhibited the phagocytosis of cholesterol by macrophage and decreased the formation of foam cells (Oh et al., 2009). Increased production of matrix metalloproteinases (MMP) led to instability and fracture of plaques and thrombogenesis. A study revealed an important biological function of vitamin $\mathrm{D}$ in the regulation of expression and activities of MMP-2 and MMP-9 (Halder \& Osteen, 2013). A cohort study also showed both Vitamin D deficiency and Vitamin D insufficiency are associated with subclinical atherosclerosis, potentially suggesting an increased cardiovascular risk in these clinical settings (Lupoli et al., 2017).

$25(\mathrm{OH}) \mathrm{D}$ deficient and insufficient in elderly diabetes could activate artery chronic inflammatory responses, and then accelerate the process of atherosclerosis. Active vitamin D receptor controls the process of atherosclerosis through regulating inflammatory cytokines, manifesting inhibiting the level of TNF- $\alpha$ which promotes atherosclerosis but increasing the level of IL-10 which resists atherosclerosis (Schleithoff et al., 2006). In vitro experiments demonstrated that active vitamin D could inhibit the level of IL- 6 and TNF- $\alpha$ in a dose-dependent way. Clinical observation also found that $25(\mathrm{OH}) \mathrm{D}$ and TNF- $\alpha$ were negatively correlated. Vitamin D regulated platelet aggregation and thrombogenesis, vitamin D receptor activation could increase the expression of thrombus regulatory proteins and inhibit the expression of tissue factors (Wu-Wong, 2009).

Our study also found that elderly diabetes in 25(OH)D deficiency group and insufficiency group had an obvious high level of LVMI, and the proportion of myocardial hypertrophy in deficiency group remarkably increased. This supported that vitamin D could participate in the myocardial remodelling. As we known, myocardial hypertrophy and myocardial remodelling are highly associated with renin angiotensin aldosterone system (RASS) directly or indirectly. RASS can stimulate collagen production and matrix remodelling, activate oxidative stress response, inhibit the transduction of nitric oxide signal pathway and decrease the synthesis of elastin leading to myocardial hypertrophy or myocardial remodelling. It is reported that vitamin D is the direct negative regulator. When comparing vitamin D receptor knockout mice and wild type mice, the expression of ferritin and angiotensin II increased several times, leading to the cardiac hypertrophy and hypertension. Xiang (Xiang et al., 2009) found that the mRNA of heart ferritin increased significantly in vitamin D receptor knockout mice. Furthermore, vitamin D treatment could reduce the expression of every component of RASS in mice including ferritin, ferritin receptor, angiotensin and angiotensin 2 receptor ( Pörsti, 2008).

Physiological mechanisms of anti-atherosclerosis by vitamin D are as follows: inhibit various inflammatory responses; inhibit vascular smooth muscle cell proliferation and myocardial cell hypertrophy and proliferation; increase insulin secretion and decrease insulin resistance; regulate RASS; inhibit lipid deposition in adipocytes (Khammissa et al., 2018). So 25(OH)D deficiency and insufficiency could lead to inflammatory responses in organisms, vascular smooth muscle cell proliferation, inadequate production of insulin, insulin resistance, and then accelerate atherosclerosis.

The patients with low 25(OH)D levels has a higher target organ damage risk factor burden compared to patients with high 25(OH)D levels. From table 4, Smoking and hypertension seem to have a much higher association with risk of target organ damage than $25(\mathrm{OH}) \mathrm{D}$ levels. This could account for the increased risk of target organ damage, independently from the $25(\mathrm{OH}) \mathrm{D}$ levels.

Our study also found that elderly diabetes in the 25(OH)D deficiency group and the insufficiency group had higher level of ACR and lower level of Ccr. They also had a higher proportion in impaired kidney function when compared with the sufficiency group. This illustrated that vitamin $\mathrm{D}$ had a protective role in microvascular in vivo, which originates the anti-inflammatory of active vitamin D on the one hand and the inhibition of RASS by active vitamin $\mathrm{D}$ on the other hand, then improve the glomerular permeability and decrease protein infiltration.

\section{Conclusion}

Our study revealed that groups with low levels of vitamin D were more likely to target organ damage than those with the sufficiency group in elderly type 2 diabetes mellitus. Furthermore, the group with target organ damage had lower levels of $25(\mathrm{OH}) \mathrm{D}$ than the group without target organ damage. The difference persisted even after an adjustment for risk factors such as age, gender, smoking, hypertension and coronary heart disease, diabetes mellitus, and HBA1C. This suggests that low levels of vitamin D were associated with high target organ damage in patients with elderly type 2 diabetes. In our study also found that among three groups there were in hypertension, coronary heart disease, smoking and higher levels of LDL-C and HbA1C, which can cause target organ damage. Multiple logistic regression analysis showed that low-level 25(OH)D $(<30 \mathrm{ng} / \mathrm{ml})$ was independently associated with total target organ damage in patients with elderly type 2 diabetes and OR was 3.58. Some studies also showed that there was an association between low levels of vitamin D and cardiovascular disease, heart failure, stroke, endothelial dysfunction and atherosclerosis. Those were in line with our conclusions. Therefore, this confirmed that low levels of vitamin D was a risk factor for target organ damage in elderly type 2 diabetes, independent of 
LDL-C, hypertension, smoking, and poorly controlled diabetes. The deficiency and insufficiency of vitamin D might be involved in aggravating target organ damage. So supplementation of Vitamin $\mathrm{D}_{3}$ could reduce the risk of target organ damage and all-cause mortality (Autier et al., 2014). Further studies are needed.

As mentioned above, our study found that there was a high proportion of 25(OH)D deficiency and insufficiency in elderly diabetes, which could not only result in hyperlipemia and an increase of postprandial blood sugar, but it could also lead to coronary heart disease and the increase of target organ damage especially the myocardial hypertrophy, brain and kidney damage.

The study has several limitations. It is a retrospective study from a single center.There are many parameters which define target organ damage, but our study selected a part of the parameters. The study did not included the patients without symptoms but with stress tests positive for inducible ischaemia.

\section{Acknowledgements}

We thank for the help of Clinical Laboratory Center in Wuhan. We also thank Caihua Huang and Jie Zhang for collecting the data. Caihua Huang and Jie Zhang are the physician in gerontology department of Puai hospital.

\section{Compliance with Ethical Standards}

The authors declare that they have no conflict of interest. All procedures performed in studies involving human participants were in accordance with the Ethics Council of Puai hospital in Wuhan or national research committee and with the 1964 Helsinki declaration and its later amendments or comparable ethical standards. This article does not contain any studies with animals performed by any of the authors.

\section{References}

Autier, P., Boniol, M., Pizot, C., \& Mullie, P. (2014). Vitamin D status and ill health: A systematic review. Lancet Diabetes Endocrinol, 2(1), 76-89. https://doi.org/10.1016/S2213-8587(13)70165-7

Cigolini, M., Iagulli, M. P., \& Miconi, V. (2006). Serum 25-hydroxyvitamin D3 concentrations and prevalence of cardiovascular disease among type 2 diabetic patients. Diabetes Care, 29(3), 722-724. https://doi.org/10.2337/diacare.29.03.06.dc05-2148

Fraser, D. R. (2015). Vitamin D Deficiency and Energy Metabolism. Endocrinology, 156(6), 1933-1935. https://doi.org/10.1210/en.2015-1298

Halder, S. K., Osteen, K. G., \& Al-Hendy, A. (2013). Vitamin D3 inhibits expression and activities of matrix metalloproteinase-2 and -9 in human uterine fibroid cells. Hum Reprod, 28(9), 2407-16. https://doi.org/10.1093/humrep/det265

Herman,W. H., Petersen, M., \& Kalyani, R. R. (2017). Standards of Medical Care in Diabetes-2017. Diabetes Care, 40(Suppl. 1), S1-S135. https://doi.org/10.2337/dci17-0007

Holick, M. F., Binkley, N. C., \& Bischoff-Ferrari, H. A. (2012). Guidelines for preventing and treating vitamin D deficiency and insufficiency revisited. $J$ Clin Endocrinol Metab, 97(4), 1153-1158. https://doi.org/10.1210/jc.2011-2601

Jiang, H., \& Peng, S. (2014). The relationship between serum vitamin D and HOMA-IR in overweight elderly $\begin{array}{lllll}\text { patients. International Journal of Cardiology, 177(3), } & \text { 1100-1102. }\end{array}$ https://doi.org/10.1016/j.ijcard.2014.09.197

Khammissa, R. A. G., Fourie, J., Motswaledi, M. H., Ballyram, R., Lemmer, J., \& Feller, L. (2018). The Biological Activities of Vitamin D and Its Receptor in Relation to Calcium and Bone Homeostasis, Cancer, Immune and Cardiovascular Systems, Skin Biology, and Oral Health. Biomed Res Int, 9276380, 1-9. https://dx.doi.org /10.1155/2018/9276380

Lupoli, R., Vaccaro, A., \& Ambrosino, P. (2017). Impact of Vitamin D deficiency on subclinical carotid atherosclerosis: a pooled analysis of cohort studies. J Clin Endocrinol Metab, 102(7), 2146-2153. https://dx.doi.org/10.1210/jc.2017-00342

Martins, D., Wolf, M., \& Pan, D. (2007). Prevalence of cardiovascular risk factors and the serum levels of 25-hydroxy vitamin D in the United States: data from the Third National Health and Nutrition Examination Survey. Arch Intern Med, 167(11), 1159-1165. https://doi.org/10.1001/archinte.167.11.1159

Oh, J., Weng, S., \& Felton, S. K. (2009). 1,25(OH)2 vitamin d inhibits foam cell formation and suppresses macrophage cholesterol uptake in patients with type 2 diabetes mellitus. Circulation, 120(8), 687-698. https://dx.doi.org /10.1161/circulationaha.109.856070 
Pacifico, L., Anania, C., \& Osborn, J. F. (2011). Low 25(OH)D3 levels are associated with total adiposity, metabolic syndrome,and hypertension in Caucasian children and adolescents. European Journal of Endocrinology, 165(4), 603-611. https://doi.org/10.1530/EJE-11-0545

Papandreou, D., \& Hamid, Z. T. (2015). The Role of Vitamin D in Diabetes and Cardiovascular Disease: An Updated Review of the Literature. Dis Markers, 2015, 580474. https://doi.org/10.1155/2015/580474

Park, S., \& Lee, B. K. (2012). Vitamin D deficiency is an independent risk factor for cardiovascular disease in Koreans aged $\geq 50$ years: results from the Korean National Health and Nutrition Examination Survey. Nutr Res Pract, 6(2), 162-168. https://doi.org/10.4162/nrp.2012.6.2.162

Pittas, A. G., Nelson, J., \& Mitri, J. (2012). Plasma 25-hydroxyvitamin D and progression to diabetes in patients at risk for diabetes: an ancillary analysis in the Diabetes Prevention Program. Diabetes Care, 35(3), 565-573. https://doi.org/10.2337/dc11-1795

Pörsti, I. H. (2008). Expanding targets of vitamin D receptor activation: downregulation of several RAS components in the kidney. Kidney Int, 74(11), 1371-1373. https://doi.org/10.1038/ki.2008.424

Schleithoff, S. S., Zittermann, A., \& Tenderich, G. (2006). Vitamin D supplementation improves cytokine profiles in patients with congestive heart failure: a double-blind, randomized, placebo-controlled trial. Am J Clin Nutr, 83(4), 754-759. https://doi.org/10.1093/ajcn/83.4.754

Shlomo, M., Kenneth, S. P., Reed, L. P., \& Henry, M. P. (2005). Williams textbook of endocrinology (12th ed.). Philadelphia: Elsevier/Saunders. https://doi.org/10.4183/aeb.2016.113

Song, Y., Wang, L., \& Pittas, A. G. (2013). Blood 25-hydroxy vitamin D levels and incident type 2 diabetes: a meta-analysis of prospective studies. Diabetes Care, 36(5), 1422-1428. https://doi.org/10.2337/dc12-0962

Vos, T., Allen, C., \& Arora, M. et al. (2016). Global, regional, and national incidence, prevalence, and years lived with disability for 310 diseases and injuries, 1990-2015: a systematic analysis for the Global Burden of Disease Study 2015. Lancet, 388(10053), 1545-1602. https://doi.org/10.1016/S0140-6736(16)31678-6

Wu-Wong, J. R. (2009). Potential for vitamin D receptor agonists in the treatment of cardiovascular disease. $\mathrm{Br} J$ Pharmacol, 158(2), 395-412. https://doi.org/10.1111/j.1476-5381.2009.00171.x

Xiang, W., Kong, J., \& Chen, S. (2005). Cardiac hypertrophy in vitamin D receptor knockout mice: role of the systemic and cardiac renin-angiotensin systems. Am J Physiol Endocrinol Metab, 288(1), E125-132. https://dx.doi.org /10.1152/ajpendo.00224.2004

Xu, Y., Wang, L., \& He, J. (2013). Prevalence and Control of Diabetes in Chinese Adults. JAMA, 310(9), 948-59. https://doi.org/10.1001/jama.2013.168118

\section{Copyrights}

Copyright for this article is retained by the author(s), with first publication rights granted to the journal.

This is an open-access article distributed under the terms and conditions of the Creative Commons Attribution license (http://creativecommons.org/licenses/by/4.0/). 